\title{
Metastatic Colorectal Cancer. First Line Therapy for Unresectable Disease
}

\author{
Jorge Aparicio ${ }^{1, *(\mathbb{C}}$, Francis Esposito ${ }^{2}{ }^{\circledR}$, Sara Serrano ${ }^{3}$, Esther Falco ${ }^{4}$, Pilar Escudero ${ }^{5}$, \\ Ana Ruiz-Casado ${ }^{6}$ (D) Hermini Manzano ${ }^{7}$ and Ana Fernandez-Montes ${ }^{8}$ (D) \\ 1 Department of Medical Oncology, Hospital Universitario y Politecnico La Fe, E-46007 Valencia, Spain \\ 2 Department of Medical Oncology, Hospital Clinic, E-08041 Barcelona, Spain; ESPOSITO@clinic.cat \\ 3 Department of Medical Oncology, Hospital Universitario Sant Joan de Reus, E-43204 Reus, Spain; \\ sarusky_zgz@hotmail.com \\ 4 Department of Medical Oncology, Hospital Son Llatzer, E-07004 Palma de Mallorca, Spain; efalco@hsll.es \\ 5 Department of Medical Oncology, Hospital Clínico Universitario Lozano Blesa, E-50002 Zaragoza, Spain; \\ pescudero@salud.aragon.es \\ 6 Department of Medical Oncology, Hospital Universitario Puerta de Hierro, E-28220 Madrid, Spain; \\ aruiz.hflr@salud.madrid.org \\ 7 Department of Medical Oncology, Hospital Quirón Salud Palmaplanas, E-07004 Palma de Mallorca, Spain; \\ hermini.manzano@quironsalud.es \\ 8 Department of Medical Oncology, Complejo Hospitalario de Orense, E-32001 Orense, Spain; \\ afm1003@hotmail.com \\ * Correspondence: japariciou@seom.org; Tel.: +34-6-606563508
}

Received: 2 November 2020; Accepted: 26 November 2020; Published: 30 November 2020

\begin{abstract}
Colorectal cancer (CRC) is a commonly diagnosed malignancy. The prognosis of patients with unresectable, metastatic colorectal cancer $(\mathrm{mCRC})$ is dismal and medical treatment is mainly palliative in nature. Although chemotherapy remains the backbone of treatment, the landscape is changing with the understanding of its heterogeneity and molecular biology. First-line therapy relies on a combination of chemotherapy and targeted therapies, according to clinical patient characteristics and tumor molecular profile. Here we review current evidence from randomized clinical trials for using chemotherapy doublets or triplets, and for the addition of bevacizumab or anti-epidermal growth factor receptor (EGFR) agents. Novel therapies developed for small, selected populations are also discussed.
\end{abstract}

Keywords: colorectal cancer; metastatic disease; chemotherapy; targeted agents

\section{Introduction}

Colorectal cancer (CRC) is a commonly diagnosed malignancy and ranks among the three leading causes of cancer death in developed countries. The most common histology by far is colorectal adenocarcinoma, and we will refer to this subtype in this review. Despite improvements in screening methodologies, approximately $20 \%$ of patients are diagnosed with metastatic CRC (mCRC), which carries a 14\% 5-year survival rate. The liver is the most common and often the unique site of metastasis. Patients with Stage IV disease can occasionally undergo curative surgical resection of their metastases with curative intent. However, treatment of $\mathrm{mCRC}$ is for the most part palliative in nature.

For patients with unresectable mCRC (representing more than $80 \%$ of this population), median survival has significantly increased up to 30 months due to advances in multimodal management, modern cytotoxic chemotherapy (CT) and the introduction of targeted agents. Treatment of mCRC requires a multidisciplinary approach because there are multiple therapeutic options and clinical decision-making is complex. Treatment goals are to prolong overall survival, to improve symptoms of disease and to maintain quality of life for as long as possible [1]. 
Relevant factors for selecting therapy are disease-related characteristics (clinical presentation, tumor burden, resectability and tumor biology), patient-related factors (performance status, age, comorbidity, socioeconomic factors and expectations) and treatment-related factors (toxicity profile and administration schedule). Results of molecular research have demonstrated the need to profile each mCRC for RAS and BRAF mutations. A better understanding of the heterogeneity of mCRC, including primary tumor location (sidedness), microsatellite instability (MSI) status and other clinically actionable tumor aberrations, is reshaping the therapeutic landscape [2].

Currently, first-line treatment relies on a CT combination, often in association with a biologic agent, according to the individual molecular status. Here we review current evidence from randomized clinical trials (RCTs) for using CT doublets or triplets, and for the addition of bevacizumab or anti-epidermal growth factor receptor (EGFR) agents, in the first-line treatment of patients with mCRC. Novel therapies developed for small, selected populations are also discussed.

\section{Chemotherapy}

Systemic combination CT represents the keystone of treatment for mCRC. Its use improves patient survival and quality of life in comparison with supportive care. Early introduction of treatment has been shown to be superior to treatment delay until the onset of symptoms. Fluoropyrimidines (FPs) constitute the backbone of combination schemes. There are mainly two alternatives, namely 5-fluorouracil (5-FU), administered intravenously, and capecitabine. 5-FU should be used by continuous infusion (CI) because it is more effective and less toxic than bolus administration but requires the implantation of a central venous access device. Capecitabine presents a similar clinical activity and tolerance, with the advantage of its oral administration. RCTs have shown comparable efficacy for both agents, either in monotherapy or in combination. As single agents, they offer response rates (RRs) of about $20 \%$ and median overall survival (OS) of 12 months. Toxicity profiles are somewhat different as CI 5-FU induces neutropenia and thromboembolic events more frequently, whereas capecitabine use is associated with a higher incidence of diarrhea and hand-foot syndrome.

By 2000, two new active agents in $\mathrm{mCRC}$ had been introduced, namely oxaliplatin (a platinum derivate) and irinotecan (a camptothecin inhibiting topoisomerase I). Their association with either 5-FU or capecitabine significantly improves all parameters of treatment efficacy. Four RCTs have shown that first-line oxaliplatin- or irinotecan-based combination CT schedules offer a similar RR of $34-55 \%$, time to progression (TTP) of 7-8 months and median OS of 14-21 months [3]. Thus, they can be used indistinctly in this clinical setting. Oxaliplatin induces more neurotoxicity and thrombocytopenia, while irinotecan use is more commonly associated with diarrhea and leukocytopenia.

The proportion of patients exposed to all active drugs (FPs, oxaliplatin and irinotecan), either simultaneously or sequentially, strongly correlates with median survival in published large Phase III trials. The likelihood of receiving them is lower with the sequential single-agent treatment strategy than when using a sequence of combination therapies [4]. The main doublet therapies used in first-line treatment are FOLFIRI (CI 5-FU plus irinotecan), FOLFOX (CI 5-FU plus oxaliplatin) and XELOX (capecitabine plus oxaliplatin). Efficacy parameters appear similar although toxicity profiles differ. XELIRI (capecitabine plus irinotecan) is less commonly used due to a higher incidence of severe diarrhea. The triple therapy with FOLFOXIRI has been compared with FOLFOX or FOLFIRI in three trials; superiority for FOLFOXIRI in terms of RR, PFS and OS was suggested in two of them. However, grade 3 to 4 toxic effects were more common with the triplet [5].

The integration of targeted agents (mainly antiangiogenic drugs and anti-EGFR agents) into CT combination schedules has further improved efficacy parameters and survival outcomes, as discussed below. Table 1 shows a summary of the main RCTs of first-line CT schedules for patients with unresectable $\mathrm{mCRC}$ evaluating $\mathrm{CT}$ doublets vs. triplets and investigating the addition of either bevacizumab or anti-EGFRs [6-27]. They have been categorized by the quality of design and the achievement of study objectives. The ESMO-Magnitude of Clinical Benefit Scale version 1.1 [28] was also used to assess them. 
Table 1. Main randomized clinical trials in first-line treatment for patients with metastatic colorectal cancer (mCRC).

\begin{tabular}{|c|c|c|c|c|c|c|c|c|c|}
\hline $\begin{array}{l}\text { Author, Journal } \\
\text { Year (ref) }\end{array}$ & $\mathbf{N}$ & Treatments & HR PFS/OS $<0.8$ & $\begin{array}{l}\text { Adequate } \\
\text { Control Arm }\end{array}$ & $\begin{array}{l}\text { PFS Censored } \\
<20 \% \text { at } 2 y\end{array}$ & $\begin{array}{l}\text { Any Change in } \\
\text { Primary End- } \\
\text { Point or Sample }\end{array}$ & $\begin{array}{l}\text { Achieved Pre- } \\
\text { Specified } \\
\text { Objective }\end{array}$ & Quality Design & ESMO/MCBS 1.1 \\
\hline \multicolumn{10}{|l|}{$\begin{array}{l}\text { Bevacizumab vs. } \\
\text { no bevacizumab }\end{array}$} \\
\hline $\begin{array}{l}\text { Kabbinavar F, } \\
\text { JCO } 2003 \text { [6] }\end{array}$ & 104 & bev plus FU vs. FU & $0.54 / 0.86 \cdot 0.62$ & no & NA & no & NA & 2 of 5 & 1 of 3 \\
\hline $\begin{array}{l}\text { Kabbinavar FF, } \\
\text { JCO } 2005[7]\end{array}$ & 209 & bev plus FU vs. FU & 0.5/0.79. 0.63 & no & yes & no & no & 3 of 5 & 0 of 3 \\
\hline $\begin{array}{c}\text { Hurwitz H, } \\
\text { NEJM } 2004 \text { [8] }\end{array}$ & 813 & bev plus IFL vs. IFL & $0.54 / 0.66 \cdot 0.95$ & yes & yes & no & yes & 4 of 5 & 2 of 3 \\
\hline $\begin{array}{l}\text { Saltz LB, JCO } \\
2008 \text { [9] }\end{array}$ & 1401 & $\begin{array}{c}\text { bev plus } \\
\text { FOLFOX/CAPOX vs } \\
\text { FOLFOX/CAPOX }\end{array}$ & $0.83 / 0.89 .0 .93$ & yes & yes & no & no & 3 of 5 & 0 of 3 \\
\hline $\begin{array}{l}\text { Tebbutt NC, } \\
\text { JCO } 2010[10]\end{array}$ & 471 & $\begin{array}{l}\text { bev plus cap or cap/mit } \\
\text { vs. cap or } \\
\text { cap/mit }\end{array}$ & $0.61 / 0.86 \cdot 0.71$ & no & yes & no & yes & 4 of 5 & 0 of 3 \\
\hline $\begin{array}{l}\text { Stathopoulos GP, } \\
\text { Oncology } 2010 \text { [11] }\end{array}$ & 222 & bev plus IFL vs. IFL & NA & no & NA & no & NA & 1 of 5 & 0 of 3 \\
\hline $\begin{array}{l}\text { Guan ZZ, Chin J } \\
\text { Cancer 2011 [12] }\end{array}$ & 214 & bev plus IFL vs. IFL & $0.44 / 0.62 .0 .71$ & no & yes & NA & NA & 2 of 5 & 2 of 3 \\
\hline $\begin{array}{c}\text { Pasardi A, } \\
\text { Ann Oncol } 2015 \text { [13] }\end{array}$ & 376 & $\begin{array}{c}\text { bev plus FOLFIRI or } \\
\text { FOLFOX vs } \\
\text { FOLFIRI or FOLFOX }\end{array}$ & $0.86 / 1.13 .0 .76$ & yes & yes & yes & no & 3 of 5 & 0 of 3 \\
\hline $\begin{array}{c}\text { Loupakis F, } \\
\text { NEJM } 2014 \text { [14] }\end{array}$ & 508 & $\begin{array}{l}\text { bev plus FOLFOXIRI vs. } \\
\text { FOLFIRI }\end{array}$ & 0.75/0.79. 0.94 & yes & yes & no & yes & 4 of 5 & 0 of 3 \\
\hline \multicolumn{10}{|l|}{$\begin{array}{l}\text { Anti-EGFR vs. } \\
\text { no anti-EGFR in } \\
\text { RAS WT }\end{array}$} \\
\hline $\begin{array}{l}\text { Van Cutsem E, } \\
\text { JCO 2015 [15] }\end{array}$ & $430 / 1198$ & $\begin{array}{l}\text { cet plus FOLFIRI vs. } \\
\text { FOLFIRI }\end{array}$ & $0.56 / 0.69 .0 .81$ & yes & no & yes & no & 1 of 5 & 3 of 3 \\
\hline $\begin{array}{c}\text { Maugham TS, } \\
\text { Lancet } 2011 \text { [16] }\end{array}$ & $729 / 1630$ & $\begin{array}{l}\text { cet plus FOLFOX or } \\
\text { CAPOX vs } \\
\text { FOLFOX or CAPOX }\end{array}$ & 0.96/1.04. 0.92 & yes & yes & yes & no & 2 of 5 & 0 of 3 \\
\hline $\begin{array}{c}\text { Tveit KM, } \\
\text { JCO } 2012 \text { [17] }\end{array}$ & $274 / 571$ & cet plus FLOX vs. FLOX & 1.07/1.14. 0.93 & no & yes & yes & no & 1 of 5 & 0 of 3 \\
\hline $\begin{array}{c}\text { Douillard JY, } \\
\text { NEJM } 2013 \text { [18] }\end{array}$ & $512 / 1183$ & $\begin{array}{c}\text { pani plus FOLFOX vs. } \\
\text { FOLFOX }\end{array}$ & $0.72 / 0.78 \cdot 0.92$ & yes & no & yes & no & 1 of 5 & 2 of 3 \\
\hline $\begin{array}{c}\text { Bokemeyer C, Eur J } \\
\text { Cancer } 2015 \text { [19] }\end{array}$ & $87 / 297$ & $\begin{array}{l}\text { cet plus FOLFOX vs. } \\
\text { FOLFOX }\end{array}$ & $0.53 / 0.94 .0 .56$ & yes & yes & yes & no & 3 of 5 & 0 of 3 \\
\hline Qin S, JCO 2018 [20] & 393 & $\begin{array}{l}\text { cet plus FOLFOX vs. } \\
\text { FOLFOX }\end{array}$ & $0.69 / 0.76 \cdot 0.91$ & yes & yes & yes & no & 2 of 5 & 1 of 3 \\
\hline
\end{tabular}


Table 1. Cont

\begin{tabular}{|c|c|c|c|c|c|c|c|c|c|}
\hline $\begin{array}{c}\text { Author, Journal } \\
\text { Year (ref) }\end{array}$ & $\mathbf{N}$ & Treatments & HR PFS/OS $<0.8$ & $\begin{array}{l}\text { Adequate } \\
\text { Control Arm }\end{array}$ & $\begin{array}{l}\text { PFS Censored } \\
<20 \% \text { at } 2 y\end{array}$ & $\begin{array}{l}\text { Any Change in } \\
\text { Primary End- } \\
\text { Point or Sample }\end{array}$ & $\begin{array}{l}\text { Achieved Pre- } \\
\text { Specified } \\
\text { Objective }\end{array}$ & Quality Design & ESMO/MCBS 1.1 \\
\hline \multicolumn{10}{|l|}{$\begin{array}{l}\text { Anti-EGFR vs. } \\
\text { bevacizumab in } \\
\text { RAS WT }\end{array}$} \\
\hline $\begin{array}{c}\text { Venook AP, } \\
\text { JAMA } 2017 \text { [21] }\end{array}$ & $474 / 1137$ & $\begin{array}{l}\text { bev plus FOLFOX or } \\
\text { FOLFIRI vs } \\
\text { cet plus FOLFOX or } \\
\text { FOLFIRI }\end{array}$ & $1.03 / 0.83 .1 .24$ & yes & NA & yes & NA & 1 of 5 & 1 of 3 \\
\hline $\begin{array}{c}\text { Heinemann V, } \\
\text { Lancet Onol } \\
2014 \text { [22] }\end{array}$ & $342 / 592$ & $\begin{array}{c}\text { bev plus FOLFIRI vs. } \\
\text { cet plus } \\
\text { FOLFIRI }\end{array}$ & 0.93/0.7. 1.32 & yes & NA & yes & NA & 1 of 5 & 3 of 3 \\
\hline $\begin{array}{l}\text { Schwartzberg LS, } \\
\text { JCO } 2014 \text { [23] }\end{array}$ & $170 / 283$ & $\begin{array}{c}\text { bev plus FOLFOX vs. } \\
\text { pani plus } \\
\text { FOLFOX }\end{array}$ & $0.65 / 0.62 .1 .04$ & yes & yes & yes & NA & 2 of 5 & 3 of 3 \\
\hline \multicolumn{10}{|c|}{ Triplets vs. doublets } \\
\hline $\begin{array}{l}\text { Souglakos J, Br J } \\
\text { Cancer 2006 [24] }\end{array}$ & 283 & FOLFIRI vs. FOLFOXIRI & $0.83 / \mathrm{NA}$ & no & yes & no & no & 2 of 5 & 0 of 3 \\
\hline $\begin{array}{c}\text { Falcone A, } \\
\text { JCO } 2007 \text { [25] }\end{array}$ & 244 & FOLFOXIRI vs. FOLFIRI & 0.63/0.7. 0.9 & no & yes & no & yes & 3 of 5 & 2 of 3 \\
\hline $\begin{array}{c}\text { Loupakis F, } \\
\text { NEJM } 2014 \text { [14] }\end{array}$ & 508 & $\begin{array}{c}\text { bev plus FOLFOXIRI vs. } \\
\text { FOLFIRI }\end{array}$ & 0.75/0.79. 0.94 & yes & yes & no & yes & 4 of 5 & 0 of 3 \\
\hline $\begin{array}{c}\text { Sastre J, } \\
\text { JCO } 2019 \text { [26] }\end{array}$ & 349 & $\begin{array}{c}\text { Bev plus FOLFOX vs. } \\
\text { bev plus } \\
\text { FOLFOXIRI }\end{array}$ & $0.64 / 0.84 .0 .76$ & yes & NA & no & yes & 3 of 5 & 1 of 3 \\
\hline $\begin{array}{l}\text { Cremolini C, Lancet } \\
\text { Oncol } 2020 \text { [27] }\end{array}$ & 679 & $\begin{array}{l}\text { bev plus FOLFOX the bev } \\
\text { plus FOLFIRI vs. } \\
\text { bev plus FOLFOXIRI } \\
\text { then bev plus } \\
\text { FOLFOXIRI }\end{array}$ & 0.79/0.82. 0.96 & yes & yes & no & yes & 3 of 5 & 1 of 3 \\
\hline
\end{tabular}

HR: hazard ratio, PFS: progression-free survival, OS: overall survival, NA: not available, ESMO/MCBS 1.1: European Society of Medical Oncology Magnitude of Clinical Benefit Scale version 1.1. [28] 


\section{Addition of Bevacizumab to Chemotherapy}

Patients with RAS mutations represent approximately $50 \%$ of the mCRC population. They have fewer treatment alternatives than RAS wild-type patients and also display a worse prognosis (hazard ratio of 1.5-2 for OS). Furthermore, tumor sidedness per se has limited influence on treatment decision in this setting. Multiple clinical trials have shown that tumors with any activating mutation of KRAS or NRAS (exons 2-4) do not benefit from anti-EGFR therapies. Their use can even be detrimental, and so they are contraindicated.

In contrast, bevacizumab, a monoclonal antibody directed against the circulating vascular endothelial growth factor A (VEGF-A), has been authorized since 2004 in combination with CT for the first-line treatment of patients with $\mathrm{mCRC}$, independently of the RAS mutational status. Its toxicity profile is well known, predictable and manageable. Its main adverse events are arterial hypertension, proteinuria, arterial thrombotic events, bowel perforation (uncommon), bleeding and wound healing problems. Bevacizumab induces a consistent improvement in PFS with any of the CT schemes (monotherapy or multiagent) employed in first-line treatment, so its use is standard for most patients with no formal contraindication. The combination of bevacizumab with CT doublets induces objective responses of around 45\%, median PFS of 9-10 months and median OS of nearly 24 months. However, the relative added efficacy in terms of survival increment is greater when bevacizumab is combined with less active CT schedules or FP monotherapy.

The addition of the antiangiogenic agent bevacizumab has been evaluated in nine comparative clinical trials [6-14] (Table 1), and three of them achieved their prespecified objective. Quality of trial design was quite variable. Significant benefit in survival was seen in only two of them, both using the bolus 5-FU IFL (irinotecan, fluorouracil and leucovorin) regimen, which is considered obsolete nowadays.

Bevacizumab provides a significant incremental gain in PFS when it is added to CT regimens such as 5-FU/leucovorin or bolus IFL, but this gain seems to be reduced when it is combined with more active CT schedules like FOLFOX, XELOX or FOLFIRI. Two trials assessed the combination of bevacizumab with either FOLFOXIRI or FOLFOX and found increased RR. There is no predictive biomarker of bevacizumab efficacy, and patients with either wild-type or mutant RAS may benefit from this therapy.

Recommendation:

In the RAS mutated population, standard first-line treatment consists of a CT doublet, generally associated with bevacizumab, if no contraindications are present.

\section{Addition of Anti-EGFR Agents to Chemotherapy}

Today, determination of RAS and BRAF mutational status is preceptive in order to select the most appropriate treatment for fit patients with unresectable mCRC. RAS mutations are negative predictors of the efficacy of anti-EGFR agents and should always be ruled out before their use. BRAF mutation (e.g., V600E) is less common and confers a poor prognosis. Approximately $40 \%$ of patients are RAS and BRAF wild type.

RAS mutation status allows the selection of individuals who might benefit from strategies targeting the EGFR [29]. The anti-EGFR monoclonal antibodies cetuximab and panitumumab should only then be prescribed for patients whose tumors are RAS wild type (KRAS exons 2, 3 and 4 and NRAS exons 2,3 and 4). The addition of cetuximab or panitumumab to either FOLFIRI or FOLFOX significantly increases patient OS from 20 to $26-28$ months $[15,18]$. However, it is also associated with increased grade 3-4 toxic events (mainly acneiform rash, infusional reactions, diarrhea and hypomagnesemia). Direct comparative studies of cetuximab vs. panitumumab in combination with CT doublets containing CI 5-FU have not shown efficacy differences between both monoclonal antibodies; nowadays, they are considered equivalent. In contrast, the association of anti-EGFR antibodies with either capecitabine or bolus 5-FU plus oxaliplatin is not recommended due to suboptimal results $[16,17]$.

A total of six clinical trials have evaluated the role of anti-EGFR agents in first-line therapy [15-20] (Table 1). Most of them were planned for the overall mCRC population and then reanalyzed for RAS 
wild-type patients. None of them achieved the prespecified objective. Quality of trial design was variable. Significant benefit in survival was observed in half of them. RR and PFS were significantly increased in RAS wild-type patients, whereas the opposite was seen in those with any RAS mutation (negative predictive value).

Recommendation:

CT doublets with anti-EGFR are recommended for fit patients with unresectable mCRC and RAS wild-type tumors.

\section{Bevacizumab vs. Anti-EGFRs}

The addition of both bevacizumab and anti-EGFR agents to combination CT has been shown to be detrimental and should not be used in this setting [30,31].

Data from three head-to-head first-line trials evaluating the activity of anti-EGFR versus bevacizumab in combination with CT doublets for RAS wild-type patients have been reported [21-23] (Table 1). Results were discordant and thus nonconclusive. None of them achieved the prespecified end-point, and PFS was equivalent in all three. However, increased RR and a trend toward better survival were observed with anti-EGFR.

Primary tumor location may influence the treatment selection. Results from a joint analysis of trials with anti-EGFR antibodies plus CT showed a greater benefit in left-sided tumors, while greater benefit was observed for right-sided cancers when CT was given alone or combined with bevacizumab [32]. In RAS mutated tumors, first-line treatment should include bevacizumab plus $C T$, independently of primary site.

Recommendation:

For left-sided, RAS wild-type tumors, the combination of CT plus anti-EGFR might be considered elective.

\section{Doublets vs. Triplets}

5-FU, oxaliplatin and irinotecan are used step by step through two-drug regimens (FOLFOX/XELOX, FOLFIRI/XELIRI), with or without monoclonal antibodies. However, not all patients receive all three of these drugs because their condition may not allow second-line treatment. The optimal sequencing has not yet been established, and some Phase III trials had shown that upfront treatment with 5-FU, oxaliplatin and irinotecan with or without bevacizumab (FOLFOXIRI regimen) can improve outcomes for patients with mCRC [14,24-27] (Table 1).

In a recent meta-analysis of eight RCTs, FOLFOXIRI was associated with improvements in efficacy outcomes, notably with a $25 \%$ survival increase. FOLFOXIRI was also associated with increased grade 3-4 toxicity [5]. A propensity score-adjusted method was conducted to provide an estimation of the benefit from the addition of bevacizumab to FOLFOXIRI. In the absence of a randomized comparison, the addition of bevacizumab to FOLFOXIRI provided significant benefit in PFS and OS, supporting its use as upfront treatment for mCRC patients [33].

Less evidence exists about the treatment with anti-EGFR and triplet therapy. A randomized Phase II trial was recently presented, comparing mFOLFOXIRI plus panitumumab versus FOLFOXIRI in 96 RAS WT patients. ORR and secondary resections of metastases were increased, PFS was similar and OS showed a trend in favor of the panitumumab-containing arm [34].

TRIBE-2 compared a preplanned strategy of upfront FOLFOXIRI followed by the reintroduction of the same regimen after disease progression versus a sequence of mFOLFOX6 and FOLFIRI doublets, in combination with bevacizumab. This Phase III trial showed that upfront FOLFOXIRI plus bevacizumab seems to be a preferable therapeutic strategy in terms of PFS and OS [27].

In most clinical trials, the benefits of triplets are more evident for fit, younger patients with no comorbidity and no prior exposition to oxaliplatin in the adjuvant setting. Based on limited individual patient data, several guidelines recommended FOLFOXIRI plus bevacizumab for patients with BRAF mutation. However, a recent meta-analysis has questioned this recommendation [33].

Recommendation: 
FOLFOXIRI with or without bevacizumab is associated with improvements in efficacy outcomes (OS, PFS, RR) in mCRC at the expense of increased toxicity.

Table 2 summarizes current recommendations for first-line treatment according to the individual molecular profile and tumor sidedness.

Table 2. Current recommendations for first-line treatment according to the individual molecular profile and tumor sidedness.

\begin{tabular}{|c|c|c|c|c|c|}
\hline $\begin{array}{l}\text { Primary Tumor } \\
\text { Sidedness }\end{array}$ & Right & Left & Left & Left & Any \\
\hline Molecular profile & $\begin{array}{l}\text { Any, } \\
\text { MSS }\end{array}$ & $\begin{array}{l}\text { Native RAS and } \\
\text { BRAF, MSS }\end{array}$ & $\begin{array}{c}\text { Mutant RAS, } \\
\text { MSS }\end{array}$ & $\begin{array}{c}\text { Mutant BRAF, } \\
\text { MSS }\end{array}$ & $\begin{array}{l}\text { Any, } \\
\text { MSI }\end{array}$ \\
\hline
\end{tabular}

\section{Treatment of Other Molecularly Selected Populations}

In recent years, several clinical trials have demonstrated that small, molecularly selected subgroups of patients with mCRC may benefit from new directed therapies. Patients with MSI-high or mismatch repair deficient (dMMR) tumors represent less than $5 \%$ of $\mathrm{mCRC}$. In these cases, treatment with immunotherapy is more effective than conventional CT (with or without antiangiogenic or anti-EGFR agents), both in first [35] and successive lines of therapy [36]. V600E BRAF mutations are present in $8-15 \%$ of mCRC cases and predict a worse prognosis as well as resistance to standard combinations. The association of encorafenib and cetuximab with or without binimetinib has shown promising results in second and later lines of treatment [37] and is now being evaluated in patients receiving less pretreatment. Finally, less than $5 \%$ of the mCRC population shows HER2 amplifications (more commonly associated with rectal primaries) or NTRK fusions (more frequently in MSI-high or dMMR cases). These rare alterations are highly actionable with drugs such as trastuzumab [38] or larotrectinib [39], respectively. Nowadays, only immunotherapy with pembrolizumab has been approved for first-line treatment in patients with mCRC and MSI-high tumors.

\section{Conclusions and Perspectives}

CRC remains a leading cause of cancer death in the Western world. Knowledge of primary tumor location along with specific targetable tumor mutations is beginning to change the outlook for patients with $\mathrm{mCRC}$. Treatment of unresectable, metastatic disease mostly relies on palliative CT (generally doublets or triplets) in combination with targeted agents. Molecular profiling is creating new therapeutic options that give patients hope for increased survival. Testing for RAS and BRAF mutations, as well as MSI status, is now mandatory, as it has direct implications for current therapy. Other actionable tumor aberrations are still under active investigation. This is a rapidly changing landscape of predictive biomarkers for the selection of conventional and/or targeted therapeutic plans that will build on new perspectives in mCRC.

Author Contributions: Conceptualization and Methodology; J.A. and A.F.-M.; Writing-Original Draft Preparation: All authors; Writing-Review \& Editing: J.A. All authors have read and agreed to the published version of the manuscript.

Funding: This research received no external funding.

Conflicts of Interest: The authors declare no conflict of interest. 


\section{References}

1. Gómez-España, M.A.; Gallego, J.; González-Flores, E.; Maurel, J.; Páez, D.; Sastre, J.; Aparicio, J.; Benavides, M.; Feliu, J.; Vera, R. SEOM clinical guidelines for diagnosis and treatment of metastatic colorectal cancer (2018). Clin. Transl. Oncol. 2019, 21, 46-54. [CrossRef] [PubMed]

2. Van Cutsem, E.; Cervantes, A.; Adam, R.; Sobrero, A.; Van Krieken, J.H.; Aderka, D.; Aranda Aguilar, E.; Bardelli, A.; Benson, A.; Bodoky, G.; et al. ESMO consensus guidelines for the management of patients with metastatic colorectal cancer. Ann. Oncol. 2016, 27, 1386-1422. [CrossRef]

3. Tournigand, C.; André, T.; Achille, E.; Lledo, G.; Flesh, M.; Mery-Mignard, D.; Quinaux, E.; Couteau, C.; Buyse, M.; Ganem, G.; et al. FOLFIRI followed by FOLFOX6 or the reverse sequence in advanced colorectal cancer: A randomized GERCOR study. J. Clin. Oncol. 2004, 22, 229. [CrossRef] [PubMed]

4. Koopman, M.; Antonini, N.F.; Douma, J.; Wals, J.; Honkoop, A.H.; Erdkamp, F.L.; de Jong, R.S.; Rodenburg, C.J.; Vreugdenhil, G.; Loosveld, O.J.; et al. Sequential versus combination chemotherapy with capecitabine, irinotecan, and oxaliplatin in advanced colorectal cancer (CAIRO): A phase III randomised controlled trial. Lancet 2007, 370, 135. [CrossRef]

5. Marques, R.P.; Duarte, G.S.; Sterrantino, C.; Pais, H.L.; Quintela, A.; Martins, A.P.; Costa, J. Triplet (FOLFOXIRI) versus doublet (FOLFOX or FOLFIRI) backbone chemotherapy as first-line treatment of metastatic colorectal cancer: A systematic review and meta-analysis. Crit. Rev. Oncol. Hematol. 2017, 118, 54-62. [CrossRef] [PubMed]

6. Kabbinavar, F.; Hurwitz, H.I.; Fehrenbacher, L.; Meropol, N.J.; Novotny, W.F.; Lieberman, G.; Griffing, S.; Bergsland, E. Phase II, randomized trial comparing bevacizumab plus fluorouracil (FU)/leucovorin (LV) with FU/LV alone in patients with metastatic colorectal cancer. J. Clin. Oncol. 2003, 21, 60-65. [CrossRef]

7. Kabbinavar, F.F.; Schulz, J.; McCleod, M.; Patel, T.; Hamm, J.T.; Hecht, J.R.; Mass, R.; Perrou, B.; Nelson, B.; Novotny, W.F. Addition of bevacizumab to bolus fluorouracil and leucovorin in first-line metastatic colorectal cancer: Results of a randomized phase II trial. J. Clin. Oncol. 2005, 23, 3697-3705. [CrossRef]

8. Hurwitz, H.; Fehrenbacher, L.; Novotny, W.; Cartwright, T.; Hainsworth, J.; Heim, W.; Berlin, J.; Baron, A.; Griffing, S.; Holmgren, E.; et al. Bevacizumab plus irinotecan, fluorouracil, and leucovorin for metastatic colorectal cancer. N. Engl. J. Med. 2004, 350, 2335-2342. [CrossRef]

9. Saltz, L.B.; Clarke, S.; Díaz-Rubio, E.; Scheithauer, W.; Figer, A.; Wong, R.; Koski, S.; Lichinitser, M.; Yang, T.-S.; Rivera, F; et al. Bevacizumab in combination with oxaliplatin-based chemotherapy as first-line therapy in metastatic colorectal cancer: A randomized phase III study. J. Clin. Oncol. 2008, 26, 2013-2019. [CrossRef]

10. Tebbutt, N.C.; Wilson, K.; Gebski, V.J.; Cummins, M.M.; Zannino, D.; van Hazel, G.A.; Robinson, B.; Broad, A.; Ganju, V.; Ackland, S.P.; et al. Capecitabine, bevacizumab, and mitomycin in first-line treatment of metastatic colorectal cancer: Results of the Australasian Gastrointestinal Trials Group Randomized Phase III MAX Study. J. Clin. Oncol. 2010, 28, 3191-3198. [CrossRef] [PubMed]

11. Stathopoulos, G.P.; Batziou, C.; Trafalis, D.; Koutantos, J.; Batzios, S.; Stathopoulos, J.; Legakis, J.; Armakolas, A. Treatment of colorectal cancer with and without bevacizumab: A phase III study. Oncology 2010, 78, 376-381. [CrossRef] [PubMed]

12. Guan, Z.Z.; Xu, J.M.; Luo, R.C.; Feng, F.-y.; Wang, L.-W.; Shen, L.; Yu, S.-Y.; Ba, Y.; Liang, J. Efficacy and safety of bevacizumab plus chemotherapy in Chinese patients with metastatic colorectal cancer: A randomized phase III ARTIST trial. Chin. J. Cancer 2011, 30, 682-689. [CrossRef] [PubMed]

13. Passardi, A.; Nanni, O.; Tassinari, D.; Petracci, R.; Scarp, E.; Biggeri, A.; Milandri, C.; Vecchia, S.; Gelsomino, F.; Tamberi, S.; et al. Effectiveness of bevacizumab added to standard chemotherapy in metastatic colorectal cancer: Final results for first-line treatment from the ITACa randomized clinical trial. Ann. Oncol. 2015, 26, 1201-1207. [CrossRef] [PubMed]

14. Loupakis, F.; Cremolini, C.; Masi, G.; Lonardi, S.; Zagonel, V.; Salvatore, L.; Cortesi, E.; Tomasello, G.; Ronzoni, M.; Spadi, R.; et al. Initial therapy with FOLFOXIRI and bevacizumab for metastatic colorectal cancer. N. Engl. J. Med. 2014, 371, 1609-1618. [CrossRef] [PubMed]

15. Van Cutsem, E.; Lenz, H.J.; Köhne, C.H.; Heinemann, V.; Tejpar, S.; Melezinek, I.; Beier, F.; Stroh, C.; Rougier, P.; Krieken, J.H.J.M.; et al. Fluorouracil, leucovorin, and irinotecan plus cetuximab treatment and RAS mutations in colorectal cancer. J. Clin. Oncol. 2015, 33, 692-700. [CrossRef] [PubMed] 
16. Maughan, T.S.; Adams, R.A.; Smith, C.G.; Meade, A.M.; Seymour, M.T.; Wilson, R.H.; Idziaszczyk, S.; Harris, R.; Fisher, D.; Kenny, S.L.; et al. Addition of cetuximab to oxaliplatin-based first-line combination chemotherapy for treatment of advanced colorectal cancer: Results of the randomised phase 3 MRC COIN trial. Lancet 2011, 377, 2103-2114. [CrossRef]

17. Tveit, K.M.; Guren, T.; Glimelius, B.; Pfeiffer, P.; Sorbye, H.; Sigurdsson, S.P.F.; Kure, E.; Ikdahl, R.; Skovlund, E.; Fokstuen, T.; et al. Phase III trial of cetuximab with continuous or intermittent fluorouracil, leucovorin, and oxaliplatin (Nordic FLOX) versus FLOX alone in first-line treatment of metastatic colorectal cancer: The NORDIC-VII study. J. Clin. Oncol. 2012, 30, 1755-1762. [CrossRef]

18. Douillard, J.Y.; Oliner, K.S.; Siena, S.; Tabernero, J.; Burkes, R.; Barugel, M.; Humblet, Y.; Bodoky, G.; Cunningham, D.; Jassem, J.; et al. Panitumumab-FOLFOX4 treatment and RAS mutations in colorectal cancer. N. Engl. J. Med. 2013, 369, 1023-1034. [CrossRef]

19. Bokemeyer, C.; Köhne, C.H.; Ciardiello, F.; Lenzd, H.-J.; Heinemanne, V.; Klinkhardtf, U.; Beierg, F.; Dueckerh, K.; van Kriekeni, J.H.; Tejparj, S. FOLFOX4 plus cetuximab treatment and RAS mutations in colorectal cancer. Eur. J. Cancer 2015, 51, 1243-1252. [CrossRef]

20. Qin, S.; Li, J.; Wang, L.; Xu, J.; Cheng, Y.; Bai, Y.; Li, W.; Xu, N.; Lin, L.; Wu, Q.; et al. Efficacy and Tolerability of First-Line Cetuximab Plus Leucovorin, Fluorouracil, and Oxaliplatin (FOLFOX-4) Versus FOLFOX-4 in Patients with RAS Wild-Type Metastatic Colorectal Cancer: The Open-Label, Randomized, Phase III TAILOR Trial. J. Clin. Oncol. 2018, 36, 3031-3039. [CrossRef]

21. Venook, A.P.; Niedzwiecki, D.; Lenz, H.J.; Innocenti, F.; Fruth, B.; Meyerhardt, J.A.; Schrag, D.; Greene, C.; O'Neil, B.H.; Atkins, J.N.; et al. Effect of First-Line Chemotherapy Combined With Cetuximab or Bevacizumab on Overall Survival in Patients With KRAS Wild-Type Advanced or Metastatic Colorectal Cancer: A Randomized Clinical Trial. JAMA 2017, 317, 2392-2401. [CrossRef] [PubMed]

22. Heinemann, V.; von Weikersthal, L.F.; Decker, T.; Kiani, A.; Vehling-Kaiser, U.; Al-Batran, S.E.; Heintges, T.; Lerchenmüller, C.; Kahl, C.; Seipelt, G.; et al. FOLFIRI plus cetuximab versus FOLFIRI plus bevacizumab as first-line treatment for patients with metastatic colorectal cancer (FIRE-3): A randomised, open-label, phase 3 trial. Lancet Oncol. 2014, 15, 1065-1075. [CrossRef]

23. Schwartzberg, L.S.; Rivera, F.; Karthaus, M.; Fasola, G.; Canon, J.-L.; Hecht, J.R.; Yu, H.; Oliner, K.S.; Go, W.I. PEAK: A randomized, multicenter phase II study of panitumumab plus modified fluorouracil, leucovorin, and oxaliplatin (mFOLFOX6) or bevacizumab plus mFOLFOX6 in patients with previously untreated, unresectable, wild-type KRAS exon 2 metastatic colorectal cancer. J. Clin. Oncol. 2014, 32, 2240-2247. [CrossRef] [PubMed]

24. Souglakos, J.; Androulakis, N.; Syrigos, K.; Polyzos, A.; Ziras, N.; Athanasiadis, A.; Kakolyris, S.; Tsousis, S.; Kouroussis, C.; Vamvakas, L.; et al. FOLFOXIRI (folinic acid, 5-fluorouracil, oxaliplatin and irinotecan) vs. FOLFIRI (folinic acid, 5-fluorouracil and irinotecan) as first-line treatment in metastatic colorectal cancer (MCC): A multicentre randomised phase III trial from the Hellenic Oncology Research Group (HORG). Br. J. Cancer 2006, 94, 798-805. [CrossRef]

25. Falcone, A.; Ricci, S.; Brunetti, I.; Pfanner, E.; Allegrini, G.; Barbara, C.; Crino, L.; Benedetti, G.; Evangelista, W.; Fanchini, L.; et al. Phase III trial of infusional fluorouracil, leucovorin, oxaliplatin, and irinotecan (FOLFOXIRI) compared with infusional fluorouracil, leucovorin, and irinotecan (FOLFIRI) as first-line treatment for metastatic colorectal cancer: The Gruppo Oncologico Nord Ovest. J. Clin. Oncol. 2007, 25, 1670-1676. [CrossRef]

26. Sastre, J.; Vieitez, J.M.; Gomez-España, M.A.; Gil, S.; Salud, A.; Graña, B.; Garcia-Alfonso, P.; Martinez de Castro, E.; Quintero, G.; Reina-Zoilo, J.J.; et al. Randomized phase III study comparing FOLFOX + bevacizumab versus folfoxiri + bevacizumab (BEV) as 1st line treatment in patients with metastatic colorectal cancer (mCRC) with $\geq 3$ baseline circulating tumor cells (bCTCs). J. Clin. Oncol. 2019, $37,3507$. [CrossRef]

27. Cremolini, C.; Antoniotti, C.; Rossini, D.; Lonardi, S.; Loupakis, F.; Pietrantonio, F.; Bordonaro, R.; PiaLatiano, T.; Tamburini, E.; Santini, D.; et al. Upfront FOLFOXIRI plus bevacizumab and reintroduction after progression versus mFOLFOX6 plus bevacizumab followed by FOLFIRI plus bevacizumab in the treatment of patients with metastatic colorectal cancer (TRIBE2): A multicentre, open-label, phase 3, randomised, controlled trial. Lancet Oncol. 2020, 21, 497-507. [CrossRef] 
28. Cherny, N.I.; Dafni, U.; Bogaerts, J.; Latino, N.J.; Pentheroudakis, G.; Douillard, J.-Y.; Tabernero, J.; Zielinski, C.; Piccart, M.J.; de Vries, E.G.E. ESMO-Magnitude of Clinical Benefit Scale version 1.1. Ann. Oncol. 2017, 28, 2340-2366. [CrossRef]

29. Sorich, M.J.; Wieses, M.D.; Rowland, A.; Kichenadasse, G.; Mckinnon, R.A.; Karapetis, C.S. Extended RAS mutations and antiEGFR monoclonal antibody survival benefit in metastatic colorectal cancer: Meta-analysis of randomized, controlled trials. Ann. Oncol. 2015, 26, 13-21. [CrossRef]

30. Hecht, J.R.; Mitchell, E.; Chidiac, T.; Scroggin, C.; Hagenstad, C.; Spigel, D.; Marshall, J.; Cohn, A.; McCollum, D.; Stella, P.; et al. A randomized phase IIIB trial of chemotherapy, bevacizumab, and panitumumab compared with chemotherapy and bevacizumab alone for metastatic colorectal cancer. J. Clin. Oncol. 2009, 27, 672-680. [CrossRef]

31. Tol, J.; Koopman, M.; Cats, A.; Rodenburg, C.J.; Creemers, G.J.M.; Schrama, J.G.; Erdkamp, F.L.G.; Vos, A.H.; van Groeningen, C.J.; Sinnige, H.A.M.; et al. Chemotherapy, bevacizumab, and cetuximab in metastatic colorectal cancer. N. Engl. J. Med. 2009, 360, 563-572. [CrossRef] [PubMed]

32. Arnold, D.; Lueza, B.; Douillard, J.-Y.; Peeters, M.; Lenz, H.-J.; Venook, A.; Heinemann, V.; Van Cutsem, E.; Pignon, J.-P.; Tabernero, J.; et al. Prognostic and predictive value of primary tumour side in patients with RAS wild-type metastatic colorectal cancer treated with chemotherapy and EGFR directed antibodies in six randomized trials. Ann. Oncol. 2017, 28, 1713-1729. [CrossRef] [PubMed]

33. Cremolini, C.; Antoniotti, C.; Stein, A.; Bendell, J.; Gruenberger, T.; Rossini, D.; Masi, G.; Ongaro, E.; Hurwitz, H.; Falcone, A.; et al. Individual patient data meta-analysis of FOLFOXIRI plus bevacizumab versus doublets plus bevacizumab as initial therapy of unresectable metastatic colorectal cancer. J. Clin. Oncol. 2020, 38, 3314-3324. [CrossRef]

34. Modest, D.P.; Martens, U.M.; Riera-Knorrenschild, J.; Greeve, J.; Florschutz, A.; Wessendorf, S.; Ettrich, T.; Kanzler, S.; Norenberg, D.; Ricke, J.; et al. FOLFOXIRI Plus Panitumumab As First-Line Treatment of RAS Wild-Type Metastatic Colorectal Cancer: The Randomized, Open-Label, Phase II VOLFI Study (AIO KRK0109). J. Clin. Oncol. 2020, 37, 3401-3411. [CrossRef] [PubMed]

35. Andre, T.; Shiu, K.K.; Kim, T.W.; Jensen, B.V.; Jensen, L.H.; Punt, C.J.; Smith, D.M.; Garcia-Carbonero, R.; Benavides, M.; Gibbs, P.; et al. Pemnrolizumab versus chemotherapy for microsatellite instability-hgh/mismatch repair deficient metastatic colorectal cancer: The phase 3 KEYNOTE-177 study. J. Clin. Oncol. 2020, 38, LBA4. [CrossRef]

36. Le, D.T.; Uram, J.N.; Wang, H.; Bartlett, B.R.; Kemberling, H.; Eyring, A.D.; Skora, A.D.; Luber, B.S.; Azad, N.S.; Laheru, D.; et al. PD-1 blockade in tumors with mismatch-repair deficiency. N. Engl. J. Med. 2015, 372, 2509-2520. [CrossRef]

37. Kopetz, S.; Grothey, A.; Yaeger, R.; Van Cutsem, E.; Desai, J.; Yoshino, T.; Wasan, H.; Ciardiello, F.; Loupakis, F.; Hong, Y.S.; et al. Encorafenib, Binimetinib, and Cetuximab in BRAF V600E-Mutated Colorectal Cancer. N. Engl. J. Med. 2019, 381, 1632-1643. [CrossRef]

38. Sartore-Bianchi, A.; Trusolino, L.; Marttino, C.; Bencardino, K.; Lonardi, S.; Bergamo, F.; Zagonel, V.; Leone, F.; Depetris, I.; Martinelli, E.; et al. Dual-targeted therapy with tratuzumab and lapatinib in treatment-refractory, KRAS codon 12/13 wild type, HER2-positive metastatic colorectal cancer (HERACLES): A proof-of-concept, multicentre, open label, phase 2 trial. Lancet Oncol. 2016, 17, 738-746. [CrossRef]

39. Drilon, A.; Laetsch, T.W.; Kummar, S.; DuBois, S.G.; Lassen, U.N.; Demetri, G.D.; Nathenson, M.; Doebele, R.C.; Farago, A.F.; Pappo, A.S.; et al. Efficacy of larotrectinib in TRK fusion-positive cancers in adults and children. N. Engl. J. Med. 2018, 378, 731-739. [CrossRef]

Publisher's Note: MDPI stays neutral with regard to jurisdictional claims in published maps and institutional affiliations.

(C) 2020 by the authors. Licensee MDPI, Basel, Switzerland. This article is an open access article distributed under the terms and conditions of the Creative Commons Attribution (CC BY) license (http://creativecommons.org/licenses/by/4.0/). 